\title{
CARTA A LOS LECTORES Y LECTORAS
}

La revista Historia de la Educación Latinoamericana que hoy tiene usted en sus manos corresponde a la edición número 25. Aborda como tema central las Escuelas Normales y está dedicada a un gran normalista, educador e historiador de la educación Guatemalteca, el Dr. Carlos González Orellana, quien como un acucioso investigador, dio un aporte significativo a la educación de ese país. El Dr. Carlos González Orellana trascendió generaciones hasta el punto que su obra se estudia en todas las carreras de educación e historia en las universidades del país pues a la fecha aún no ha sido superada y continúa siendo un referente para todo educador.

La decisión que este número de la revista incluya como tema central las Escuelas Normales, obedece a que estas instituciones han representado un gran aporte para la cultura y el desarrollo de las naciones. El origen de las Escuelas Normales data de finales del siglo XVII, cuando inician los primeros seminarios de maestros en Francia, luego pasan Alemania, Prusia, Francia, y su más alto desarrollo fue a lo largo del siglo XIX. La denominación "Escuelas Normales" está relacionada con que las mismas eran vistas como instituciones que establecían la norma de "cómo enseñar". En 1942 se funda la primera escuela normal en América, esta inicia operaciones en Santiago de Chile. Los inicios parecen estar relacionados con ciertas dificultades para operar, tal el caso que, la dificultad para encontrar personas que se dedicaran a la docencia fue uno de los principales problemas, debiendo acudir a personas con ciertas características que no siempre eran las mejores para la realización de la tarea docente. Luego vino la influencia de países ya avanzados y con experiencia en la formación de maestros, entre ellos: Bélgica, Alemania, Francia, España, Cuba, entre otros. Estos países asesoraron y dieron acompañamiento al funcionamiento de las escuelas normales en América.

Las Escuelas Normales tuvieron auge y representaron enormes avances a nivel de la cultura de los pueblos, el aporte en la formación de profesores para pre escolar y primaria, (educación básica en algunos países). Significó mucho para el desarrollo cultural y educativo de la sociedad. Como toda institución, las escuelas normales, evolucionan y se transforman, esto puede evidenciarse con lo que pasó en Europa durante las primeras décadas del siglo XX. Igual situación se presentó en América. Esa evolución representó la conversión que estas instituciones tuvieron y que las llevó a constituirse en Facultades de Educación o su similar en las universidades, en otros casos, se convirtieron en universidades pedagógicas. En algunos países se les llamó Institutos Superiores Pedagógicos. Pocos son los países que todavía conservan las Escuelas Normales, 
haciendo la función para la cual fueron creadas. Algunos hicieron hasta lo imposible por hacer que permaneciera, por lo que se convirtieron en centros de formación terciaria no universitaria o una conminación entre universitario y no universitario, como el caso de Colombia, entre otros. Su transformación no fue fácil, hay gran discusión acerca de que la transición de la formación docente a nivel universitario generó la pérdida de la mística de los docentes. Pues la universidad se limitó a la formación disciplinar, trató de desarrollar la investigación y descuidó la práctica docente y la vocación que requiere la profesión docente. Indiscutiblemente el estudiar la formación docente en las escuelas normales siempre ha sido y será un tema de interés para la educación y para la historia.

La revista Historia de la Educación Latinoamericana se organiza de manera que cuenta con varias partes, en las cuales sus componentes están bien identificados, a continuación aparece una descripción del contenido de cada una de ellas.

Aquí se presentan una brevísima idea de los artículos presentados por los autores que colaboraron con esta edición, se hace la observación que se trata de respetar las ideas centrales incluidas en los resúmenes escritos por ellos.

Se empieza con el trabajo que nos aporta Zaira Navarrete-Cazales, con el título Formación de Profesores en las Escuelas Normales de México. Siglo XX, en este trabajo ella nos plantea el panorama histórico de las escuelas normales: surgimiento, desarrollo, crisis, modelos, coyunturas políticas entre otros aspectos, además la importancia que para México tiene la escuela normal como institución formadora de maestros para los distintos niveles del sistema escolar.

Continúa Mônica Farid, desde Brasil presentándonos por medio de su artículo titulado: Escuelas Normales y formación de educadores desde una Educación para niños con discapacidad, la autora nos presenta un análisis detenido relacionado con la formación que han desarrollado las escuelas normales en su país, sobre todo hace referencia en cuanto a su contribución en la formación de los niños con discapacidad, como un componente fundamentalmente importante para la inclusión en la escuela.

Luego, Álvaro Acevedo Tarazona presenta un artículo titulado Escolarización de la enseñanza y formación de maestros, contexto sociopolitico en la Reforma Instruccionista del Estado Soberano de Santander (1863-1870), preámbulo de las Escuelas Normales en Colombia, en ese trabajo el autor nos permite una mirada profunda por medio de la cual se puede entender el contexto sociopolítico que permitió la llamada reforma instruccionista de 1870 en el Estado Soberano de Santander como inicio a la escolarización formal de la enseñanza y de las escuelas normales para la formación de maestros en Colombia.

Sigue María Fernanda Juárroz, y Judith Naidorf quienes nos presentan el artículo titulado Disyuntiva entre ciencia universal y ciencia nacional. Vinculación 
academia-sector productivo durante el desarrollismo. En este artículo las autoras hacen un planteamiento por medio del cual intentan recuperar los sucesos (debates, discursos, y acciones) que durante el período de los años 60 y 70, en la Facultad de Ciencias Exactas y Naturales de la Universidad de Buenos Aires Argentina se presentan cuando se genera una política científica al rededor del desarrollo de la llamada "Ciencia Nacional", implicando esto como lo indican las autoras el posicionamiento respecto del binomio ciencia-ideología.

Posteriormente Roger Pita, nos ilustra con su artículo titulado, Fundar escuelas para consolidar la República y formar ciudadanos. Una aproximación para el caso colombiano, 1819-1825. En este artículo se nos ilustra con un análisis relacionado con el período en referencia en el cual, el gobierno inició acciones para darle a las escuelas primarias la importancia que les correspondía. Las escuelas fueron consideradas las instituciones que transmitían la cultura a la sociedad, además quienes promovían los principios liberales y republicanos.

A continuación Elías Pizarro y Raúl Bustos, presentan desde Chile, el artículo, Educación y control político-social del Estado: Visitadores de Escuela en Tacna y Arica (1880-1900). Los autores resaltan la figura de los actores que no han sido visibles en la historia de Chile especialmente en el norte de este país, haciendo para el efecto un análisis de las funciones que debían desarrollar los visitadores de escuela, en palabras de los autores "como agentes de la acción educativa planificada desde el Estado y como mecanismo de control político y social, durante el período comprendido entre la incorporación militar de la zona de Arica. (1880) y su anexión a la soberanía chilena (1929)".

Continúa Enrique Gordillo, desde Perú, con su artículo, la Historia de la Educación Mixta y su difusión en la Educación Formal Occidental en el cual se presenta el proceso que llevó a la educación mixta en el sistema occidental tal como lo conocemos hoy en día (con un énfasis final en el proceso peruano), y el autor llega a la conclusión que, en efecto, su expansión en dicho sistema no obedeció tanto a beneficios científicamente comprobados con certeza como a presiones de índole sociológica o de índole económica.

Luego, Rafael Santos desde México hace un aporte interesante con su artículo cuyo título es El Estado mexicano y el proceso de evangelización educativo en el norte de Sinaloa, 1930-1940. En su trabajo el autor aborda la revolución cultural en el México postrevolucionario, lo cual se enmarca en el período de 1930 a 1940 en el norte de Sinaloa. En principio plantea las diferentes políticas educativas que emprendió la Secretaría de Educación Pública, para integrar grandes grupos de campesinos y obreros al Estado. Luego hace un análisis de los distintos roles que jugaron los maestros del nivel primario en el área rural.

Continúa Marcos Villela Pereira y Diogo Francos Ríos quienes con su artículo titulado Por una estética escolar brasileña en la década de 1950: La Revista Actualidades Pedagógicas y las imágenes escolares. Hacen un análisis de las imágenes de las 
escolares en dos ejemplares de la Revista de Actualidades Pedagógicas publicadas en 1955 y 1960 con la intención de señalar cómo se configuró la estética escolar en la década mencionada, en Brasil.

Continúa Diana Soto, Sandra Bernal, William Pachelo, Yules Espinosa, Liliana Paternina y Beatriz Perrello, quienes presentan desde Colombia y España, el artículo, La enseñanza de la independencia americana en Colombia y España. Los textos escolares 2009-2011. En palabras de los autores este artículo es resultado de la investigación titulada "La independencia americana en la enseñanza en Colombia y España 2009-2011", y en él nos señalan; se analizaron las maneras como el tema de la independencia americana, desde la institución educativa y el aula escolar, (con los contenidos, mensajes, iconografía de los textos, guías y procesos de enseñanza-aprendizaje) originó unos imaginarios sociales en los estudiantes de educación básica primaria (4 y 5), que asimilan hacia una nueva identidad en el imaginario de la nación en la región cundi-boyacense de Colombia, y en 2 ESO y 4 Bachillerato de la Provincia de Andalucía, España.

Luego Fuensanta Hernández y Andrés Escarbajal de Haro, y Fuensanta Monroy, nos presentan, desde España, el artículo, Deudores de Cádiz: La constitución de 1812 y la Educación. En este escrito analizan la importancia e influencia, en el ámbito educativo, que ha tenido la Constitución de 1812, los autores nos refieren esa constitución como de las más importantes en la historia de España en virtud que el nivel de importancia que se le asignó a la educación es incalculable ya que le dedican un apartado especial como nunca antes había sucedido.

En la segunda parte de la revista, encontramos dos documentos que se incluyen en la revista por la importancia de los mismos y como representación del aporte del Dr. Carlos González Orellana educador guatemalteco, a quien se le dedica la portada de esta revista, en primer lugar el Dr. Bienvenido Argueta, hace un análisis del significado de la obra Historia de la Educación de Guatemala, y los desafíos que este tiene en el futuro inmediato, posteriormente una transcripción del original de la lección inaugural del primer semestre del año 1989 del programa de maestría en docencia universitaria, en donde el doctor Carlos González Orellana, hace un análisis profundo sobre el "Surgimiento y desarrollo de la pedagogía universitaria en centro américa". 
Para finalizar estas líneas, quiero expresar un especial agradecimiento a la directora y editora general de la revista, la doctora Diana Elvira Soto Arango, por su desmedido interés por difundir la ciencia a través de un medio como este y por el dinamismo y trabajo constante por la academia iberoamericana. De igual manera especiales agradecimientos a la asistente editorial, al Comité Científico, al Comité Editorial, al Consejo Asesor Internacional, al Comité Evaluador, a los colaboradores en distintos ámbitos, a los articulistas y a usted que hoy tiene en sus manos la edición número 25, espero disfrute de la lectura y se interese por continuar cada semestre esperando la nueva edición.

Dr. Oscar Hugo López Rivas

Universidad San Carlos de Guatemala

30 junio de 2015 